\title{
Do Conflito de Atribuição no Código de Processo Civil Brasileiro
}

\author{
J. Cretella Júnior \\ Professor Titular de Direito Administrativo \\ da Faculdade de Direito da Universidade \\ de São Paulo.
}

Sumário: 1. O problema. 2. O Código de Processo Civil Atual. 3. O vocábulo "conflito". 4. Conflito de competência. 5. Conflito de atribuição. 6. Origem da confusão. 7. Comentadores do CPC anterior. 8. Comentadores do atual CPC. 9. A Emenda Constitucional. 10. Conflitos de atribuição, na prática. 11. Natureza jurídica do ato que dirime o conflito.

\section{O problema}

No Brasil, o conflito de jurisdição ou de competência somente poderá ocorrer entre autoridades judiciárias. $\mathrm{O}$ conflito de atribuições, entre autoridades judiciárias e administrativas; ou entre autoridades administrativas.

o conflito de jurisdição ou conflito de competência, que envolve sempre juízes ou tribunais, é matéria de direito processual. O conflito de atribuição, embora envolva, de um lado, juízes e tribunais, é matéria exclusiva de direito administrativo e não instituto de natureza processual.

Sendo uma das conseqüências da hierarquia, o "conflito de atribuição", no Brasil, é, dentro de cada um dos Poderes, o choque entre duas autoridades, em matéria administrativa, decorrente do fato de ambas entenderem que são competentes ou incompetentes para o desempenho de determinada atividade que nada tem de jurisdicional ou de legislativa.

Suscitado o conflito, na órbita interna de cada um dos Poderes, o superior hierárquico, para efeitos administrativos, é que vai decidir qual das duas autoridades em conflito deve desempenhar a atividade, em questão.

Suscitado o "conflito de atribuição", na órbita externa, como, por exemplo, entre autoridades administrativas e auto- 
ridades judiciárias, a questão complica-se um pouco, porque, na verdade, não existe superior hierárquico comum aos órgãos conflitantes, competente para dirimir o choque ocorrido, motivo por que a lei é que determinará a competência para resolvê-lo.

Denominamos "conflito de atribuição interno" o que se verifica entre autoridades do mesmo poder; "conflito de atribuição externo", o que ocorre entre autoridades pertencentes a poderes diversos.

Excluída, assim, qualquer idéia de jurisdição, porque, no Brasil, a autoridade administrativa não julga, "conflito de atribuição", no sentido que lhe dá o CPC, art. 124, a CF, art. 119, I, "f" e o RI do STF, art. 6. ", "e", este último, aliás, transcrevendo, ipsis litteris, o dispositivo constitucional citado, é precisamente o de "choque entre autoridades judiciárias e autoridades administrativas que se julgam competentes ou incompetentes para o desempenho de atividade administrativa"

"Conflito de atribuição", na França e nos demais países que admitem o contencioso administrativo", tem outro sentido: "conflito de competência", "conflito de jurisdição" entre duas ordens, ambas judicantes, a "ordem judiciária" e a "ordem administrativa", porque, repetimos, na França, há tribunais administrativos que julgam.

Por não atentar para este fato é que Francisco Campos, transplantando para o nosso meio disposições de países que admitem o "contencioso administrativo", introduziu no CPC de 1939 matéria incompatível com o nosso sistema jurídico, acabando por influenciar comentadores como PONTES DE MIRANDA que, ao analisar exaustivamente o CPC de 1939 e o de 1973, não percebeu o absurdo da situação.

ALFREDo BUZAID, idealizador e estruturador do atual CPC, colocou as coisas no devido lugar, ao deferir aos regimentos internos dos tribunais a tarefa da disciplinação do processo e julgamento do "conflito de atribuições" entre autoridade judiciária e autoridade administrativa.

\section{O Código de Processo Civil atual}

"Os regimentos internos dos tribunais regularão o processo e julgamento do conflito de atribuições entre autoridade judiciária e autoridade administrativa" - diz lapidarmente o CPC brasileiro, de 1973, no artigo 124. E a única referência, em todo o Código de Processo Civil, a esse tipo especial de conflito. 
O Código de Processo Civil emprega, assim, a expressão técnica e correta "conflito de atribuições" para designar o choque de competência, "em matéria administrativa", entre autoridade judiciária e autoridade administrativa, corrigindo, assim, a impropriedade do Código anterior de 1939 que, sem base alguma na realidade brasileira, aludia à possibilidade de "conflito de jurisdição" entre autoridades administrativas (art. 146 e art. 802), como se, no Brasil, as autoridades administrativas julgassem, exercessem jurisdição, o que, na verdade, não ocorre.

Realmente, como haver conflito de jurisdição entre a ordem administrativa e a ordem judiciária, se a ordem administrativa não tem a faculdade de exercer, no Brasil, funções jurisdicionais?

Ora, os conflitos de jurisdição ou conflitos de competência, matéria processual, por excelência, são exaustivamente disciplinados no Código de Processo Civil, em vigor; os conflitos da atribuição, assunto de direito administrativo, deixam de ser tratados, no mesmo Código, é claro, delegando o legislador, acertadamente, essa tarefa aos regimentos internos dos tribunais, o que também constava do Código de Processo Civil de 1939 (art. 146, I e II).

Qual o motivo por que o CPC de 1939 disciplinou tais conflitos, determinando quem tinha competência para processá-los e julgá-los e o CPC de 1973 não tratou do assunto, preceituando que a matéria ficasse a cargo dos correspondentes regimentos internos dos tribunais?

A resposta é simples. Trata-se de matéria de direito administrativo e não de matéria processual, já que, por exceção, as autoridades judiciárias também editam atos administrativos - os denominados "atos administrativos materiais". Daí a delegação para os tribunais, que deverão incluir o assunto nos "interna corporis". Assim, se editando ato administrativo ou dando origem a fato administrativo, o magistrado se julga competente ou incompetente para tal desempenho - que é função pública administrativa e não jurisdicional —, pode ocorrer que autoridade administrativa, no normal desempenho de suas funções, entre com ele em choque, por julgar-se também competente ou incompetente para o exercício da mesma tarefa. Nesse caso, os "interna corporis" estabelecerão regras para a tomada de conhecimento e solução do conflito. Suscitado e resolvido o conflito, a autoridade, considerada apta para desempenhar a tarefa, ficará encarregada de prestação da atividade que lhe foi deferida. 
Para que se compreenda bem o problema é necessário relembrar algumas noções preliminares (cf. sobre o tema o artigo que escrevemos em 1964, na Revista de Direito Processual Civil, págs. 101-109, fundada e dirigida pelo Professor ALFREDO BUZAID).

\section{O vocábulo "conflito"}

Do latim conflictu (m), acusativo de conflictus, us, m., nome da quarta declinação, o vocábulo "conflito", em qualquer dos ramos do direito, significa "choque", "controvérsia", "luta", "disputa", "embate".

A palavra pertence à mesma raiz a que se filia o verbo "confligere", que tem o sentido de "chocar-se", "abalroar", "bater", "dar de encontro". Falando de duas naves que colidiram, em célebre abalroamento, o escritor CAIO JÚLIO CÉSAR escreveu, no $D e$ bello civili, II, 6.5: "naves inter se conflixerant". Descrevendo, na Eneida, II, verso 417, a fúria dos elementos, VERGILIO disse: "adversi venti confligunt".

Raro o campo do direito em que não ocorra, a todo instante, o termo "conflito" para designar "forças opostas que se chocam", "luta entre duas tendências incompatíveis". Nesses conflitos, que são "para tomar conhecimento" ou "para não tomar conhecimento" de algo, é preciso autoridade mais alta que diga qual dos dois conflitantes deve tomar conhecimento (e depois decidir) a questão, objeto da "luta de competência".

Não é difícil compreender-se a razão desse fato, porque o direito trabalha com elementos de natureza dinâmica, em perpétuo choque, em perene contenda, em contínua luta, cabendo-lhe, nesse caso, a imediata restauração do equilíbrio ameaçado ou violado.

Além de surgir no direito judiciário penal, no direito internacional privado, no direito internacional público, no direito do trabalho, o "conflito" ou "luta de competências" é freqüente no âmbito do direito judiciário civil e no campo do direito administrativo. Tendo vários sentidos secundários, que agora não interessam, o vocábulo "conflito" tem, entre outros, um sentido particular e técnico, embora amplo, que assume grande relevância: luta de competência entre duas autoridades. As autoridades podem ser judicantes ou não-judicantes (= administrativas).

Se a função jurisdicional se caracteriza pela aplicação da lei ao fato individuado para garantia dos direitos individuais (JoÃo MENDES JÚNIOR, Direito judiciário brasileiro, $3 .^{a}$ ed., 1940, pág. 27), pode ocorrer que dois ou mais juízes (ou mesmo 
tribunais) se declarem competentes ou incompetentes para o conhecimento e julgamento da mesma causa. Nisto consiste o conflito de jurisdição, positivo, no primeiro caso, negativo no segundo.

Como, no Brasil, apenas o Poder Judiciário julga, o conflito de jurisdição diz respeito à luta de competência jurisdicional, tão somente, não ocorrendo, em hipótese alguma, conflito die jurisdição entre autoridades judiciárias e autoridades administrativas. "Pode ser levantado conflito também entre autoridades judiciárias e autoridades administrativas. Nesse caso, o conflito denomina-se, geralmente, conflito de atribuição" (MANoel AuReliano de Gusmão, Processo Civil e comercial, $4 .^{\text {a }}$ ed., 1939, vol. I, pág. 190). A observação de MANOEL AuReliano de GuSmão é perfeita, incensurável, correta.

\section{Conflito de competência}

Conflito de competência, no Brasil, é matéria de direito processual, exclusivamente, porque entre nós apenas o Poder Judiciário exerce funções jurisdicionais, pelo que é como se não existissem os artigos 146 e 802 do Código de Processo Civil de 1939, que tratam da possibilidade de choques entre autoridades que jamais poderão entrar em choque, em matéria de jurisdição. Tão só, em matéria de atribuição, poderão conflitar as autoridades administrativas e judiciárias.

Na França, tal "conflito de jurisdição" é possível, recebendo o nome técnico de "conflito de atribuição", porque, naquele país, além do Poder Judiciário, os Tribunais Administrativos exercem jurisdição. Nesse sentido, "atribuição", na França, é sinônimo de "jurisdição".

\section{Conflito de atribuição}

A expressão "conflito de atribuição", no direito universal, tem dois sentidos radicalmente diferentes: "choque entre duas autoridades administrativas, em matéria administrativa" e "choque de competência para decidir contenciosamente".

Nos países de unidade de jurisdição ou de jurisdição una, como o Brasil, em que vigora a regra "una lex, una jurisdictio", "atribuição" é "tarefa", "função", "atividade administrativa", "conjunto de poderes funcionais que órgãos ou agentes são autorizados, por lei, a exercer, no exercício do cargo", "círculo de assuntos que devem ser resolvidos, mediante a prática de fato administrativo ou da edição de ato administrativo" 
Como os três Poderes desempenham um "quantum" de Administração, existem atribuições administrativas tanto no âmbito do Poder Executivo (a regra), como na esfera do Legislativo e do Judiciário (a exceção).

Fazendo-se, pois, abstração dos Poderes (aspecto formal), para levar-se em conta, apenas, o exercício da atribuição (aspecto material), podemos dizer que "conflito de atribuições é a luta de competência administrativa entre agentes ou órgãos que se julgam, simultaneamente, aptos para o conhecimento e solução de determinado assunto, afastada, desde logo, qualquer idéia de jurisdição". Podem os conflitos de atribuição ser positivos ou negativos, internos e externos.

Se duas autoridades se acham, ambas, competentes para o exercício da atribuição administrativa, temos o conflito positivo de atribuição. Em caso contrário, ocorre o conflito negativo de atribuição.

Conflitos de atribuiçãa internos são os que se verificam dentro do mesmo Poder, quando duas autoridades entendem que são competentes ou incompetentes para o desempenho da mesma atividade ou para a edição do mesmo ato, caso em que, o superior administrativo das duas autoridades em conflito decide quem é competente para a edição do ato. Ou para o desempenho da atividade.

Nos países de "jurisdição dupla", como a França, que admitem o contencioso administrativo, "atribuição" é o mesmo que "jurisdição" Assim, "conflito de atribuição" é "conflito de jurisdição" entre autoridades-administrativas e autoridades judiciárias, porque ambas julgam, ambas têm poderes jurisdicionais.

\section{Origem da confusão}

A existência de duas ordens de jurisdições, como na França, em que, ao lado dos tribunais judiciários, existem os tribunais administrativos, dá origem aos "conflitos de atribuição", mas esta expressão designa para os franceses "choque de competência" entre a ordem administrativa e a ordem judiciária, porque "atribuição" quer dizer, na técnica do direito francês, "jurisdição", quando se trata de luta de competência entre as referidas ordens judicantes.

Nem sempre, entretanto, os "conflitos de competência" são "conflitos de atribuição", porque este nome é reservado apenas para designar os choques entre as duas ordens de jurisdições, 
a administrativa e a judiciária. Quando surgem, na França, conflitos "de jus dicere", pertencentes à mesma ordem (judiciária ou administrativa), os conflitos são de jurisdição. Resolvem-se internamente, dentro da respectiva ordem. Internamente, ainda na França, dois funcionários podem entrar em conflito sobre desempenho de tarefas. Cumpre ao chefe de ambos decidir quem deve desempenhá-las.

Há ainda os denominados conflitos de decisões (ou contrariedade de julgamentos), que diferem dos conflitos de atribuições, por não serem conflitos de competência, mas choque entre julgamentos, nos quais se evidencia uma contradição (ANDRÉ DE LAUBADÈRE, Traité élémentaire de droit administratif, 1953, págs. 283-284).

Nos países como o nosso, em que ocorre unidade de jurisdição, o contencioso administrativo não existe, desde que foi abolido pela Constituição de 1891 e reafirmado nas Magnas Cartas posteriores, conforme a regra "a lei não poderá excluir da apreciação do Poder Judiciário qualquer lesão de direito individual" (CF de 1946, art. 141, IV; CF de 1967, art. 150 $\S 4 .^{\circ} ; \mathrm{CF}$ de 1969 , art. $153, \S 4 .^{\circ}$ ).

Como o legislador processual de 1939 traduziu lei estrangeira, procurando adaptá-la a nosso direito, os artigos 146 e 802 do CPC dão a impressão de que há, no Brasil, o instituto do contencioso administrativo.

$\mathrm{O}$ artigo 802 ("O conflito de jurisdição poderá ocorrer entre autoridades judiciárias ou entre estas e as administrativas") do CPC de 1939 nunca teve sentido, diante de nossa realidade jurídica, porque se a primeira parte é correta, a segunda parte é divorciada dos fatos, pela simples razão de que não existe, no Brasil, conflito de jurisdição entre "autoridades judiciárias" e "autoridades administrativas", pois, para que tal houvesse, seria necessário que as "autoridades administrativas" julgassem, dissessem o direito e, não somente, administrassem. Ora, entre nós, as autoridades administrativas não julgam. Administram, tão só.

Não exercendo atividades jurisdicionais, mas apenas administrativas, impossível o conflito de jurisdição entre autoridades, quando somente uma delas julga - a autoridade judiciária.

Em suma, o artigo 802 do CPC de 1939 foi sempre letra morta, em nosso direito, por disciplinar matéria incompatível com a realidade dos fatos. 
Redigido de maneira apressada, durante o período ditatorial, sob evidente inspiração de países que admitiam o contencioso administrativo, o CPC de 1939 disciplinou o conflito de atribuição como se estivéssemos na França, onde, ao lado da justiça comum existe a justica especializada. O conflito nos Tribunais Gauleses é suscitado precisamente porque surgem lutas de competência "para julgar" entre duas ordens - a ordem judiciária e a ordem administrativa.

Ocorrendo o conflito, na França, o Tribunal de Conflitos é que vai decidir que autoridades devem tomar conhecimento e julgar a questão.

Transplantando-se para o Brasil dispositivos que regem esse assunto nos países de dúplice jurisdição, é claro que a incompatibilidade será total, porque não se ajusta à realidade brasileira.

O artigo 146 do CPC de 1939 está em ligação estreita com o artigo 802 do mesmo diploma processual, assinalando quais as autoridades competentes para o processo e julgamento dos "conflitos de jurisdição" entre autoridades judiciárias e administrativas, a saber, (a) o Supremo Tribunal Federal, (b) os Tribunais de Justiça (antes Tribunais de Apelação) ou (c) os próprios juízes de direito, nos demais casos. Onde se lê "conflitos de jurisdição" deve ler-se "conflitos de atribuição"

Ao passo que o CPC de 1973 não determinou quem processaria e julgaria o conflito de atribuições entre autoridades iudiciárias e autoridades administrativas, assim que suscitado, o CPC de 1939 preferiu tomar posição, indicando o órgão competente para tomar conhecimento e julgar o choque de competência. Na segunda parte, o legislador de 1939 e o de 1973 concordam: seja quem for competente para conhecer e julgar o conflito, deve fazê-lo, conforme o respectivo regimento interno, sempre levando-se em conta o que a CF determinou.

\section{Comentadores do CPC anterior}

Comentando, em 1947, o CPC de 1939, concluiu Pontes DE MiRANDA, ao referir-se ao artigo 146: "É difícil, todavia, saber-se o que foi que verdadeiramente se pretendeu" (Comentários ao CPC, Rio, 1947, vol. I, pág. $508 ; 2 .^{2}$ ed., 1958, vol. II, pág. 349).

Aceitando, sem crítica, a colocação incorreta do CPC de 1939, PONTES DE MIRANDA trata normalmente do "conflito de jurisdição entre autoridades judiciárias e administrativas" 
(Comentários ao $C P C$, Rio, $2 .^{\text {a }}$ ed., 1958, vol. II, pág. 347), escrevendo, a seguir que o CPC figurou os casos de conflito entre as autoridades judiciárias e as autoridades administrativas (Comentários ao CPC, a $^{a}$ ed., 1958, vol. II, pág. 348). E prossegue: "Para que o Tribunal de Justiça decida conflitos de jurisdição entre autoridades judiciárias e autoridades administrativas. ." (Comentários ao CPC, Rio, 2. ${ }^{\mathrm{a}}$ ed., 1958, vol. II, pág. 348). Ora, tais conflitos de jurisdição inexistem, no Brasil, porque as autoridades administrativas não julgam.

Em outro volume dos Comentários ao Código de Processo Civil de 1939, Pontes DE Miranda, ao comentar o artigo 802, reafirma, inexplicavelmente, que "ainda é possível o conflito de jurisdição entre os juízes ou tribunais ou ENTRE QUALQUER DELES E AUTORIDADES ADMINISTRATIVAS" (PONTES DE MIRANDA, Comentários ao CPC, Rio, $2 .^{2}$ ed., 1960, vol. X, pág. 345).

Por fim, a seguinte inexplicável afirmação que não encontra o menor eco em nosso direito: "O conflito entre juiz e autoridade administrativa é, tipicamente, de jurisdição" (PoNTES DE Miranda, Comentários ao CPC, Rio, 1947, vol. IV, pág. 613).

Em suma, por incrível que pareça, PonTes DE Miranda, sempre tão lúcido e veemente na crítica ao direito positivo, não atinou com o problema, aceitando, pacificamente, o absurdo das determinações do CPC de 1939, sobre o inexistente. "Conflito de jurisdição" entre autoridades judiciárias e autoridades administrativas é utopia já que, no Brasil, as autoridades administrativas nem "conhecem de processos", nem "prometem prestações jurisdicionais".

CARVAlHo SANTOS igualmente não entendeu o erro do CPC de 1939: "O Código de Processo, neste artigo que vamos comentar, admite o conflito de jurisdição entre a autoridade judiciária e a administrativa. Parece-nos que há aí impropriedade de expressão. Não há conflito de jurisdição, senão entre autoridades da mesma ordem, denominando-se conflito de atribuição, no caso de tratar-se de autoridades diversas" (Código de Processo Civil interpretado, $4 .^{\mathrm{a}}$ ed., 1955, vol. IX, pág. 143). Nesta primeira parte, CaRvalHo Santos pressentiu o erro do Código de 1939, mas não aprofundou o tema.

Carvalho Santos equivoca-se, ao dizer que "conflito de jurisdição ocorre entre autoridades da mesma ordem" e que "conflito de atribuição se verifica entre autoridades diversas" Ainda aqui, faltou precisão ao tratamento do assunto. 
No Brasil, o "conflito de jurisdição" só se dá entre autoridades judiciárias, quando discordam sobre quem é competente ou incompetente "para julgar", a passo que o "conflito de atribuições" pode ocorrer, sempre em matéria administrativa, entre autoridades da mesma ordem ou entre autoridades de ordens diversas.

Em suma, no "conflito de jurisdição", a discordância é sobre a idoneidade ou não da "prestação jurisdicional", enquanto que, no "conflito de atribuição", a discrepância é a respeito de quem é apto ou não para a "prestação administrativa".

A conclusão de CARvalho SANTos deixa perplexo o leitor, pelo absurdo que encerra: "Como quer que seja, o que se procura é que seja real, por um meio prático, a separação de poderes, evitando que o Poder Judiciário tenha ingerência no exercício das atribuições administrativas, ao mesmo tempo que não permite que a autoridade judiciária esteja à mercê de qualquer invasão estranha às suas atribuições" (Código de processo civil interpretado, $4^{\mathrm{a}}$ ed., 1955, vol. IX, pág. 143).

$\mathrm{Na}$ realidade, mediante a resolução do "conflito de atribuições" nem haverá invasão do Judiciário nas atribuições administrativas, nem o inverso ocorre, porque os respectivos regimentos internos já dispuseram e dispõem a respeito de quem resolverá o conflito, quando suscitado. Aliás, nem o Judiciário pretende administrar, nem a Administração pretende (e nem pode) julgar. Os conflitos de atribuição surgem, quando há dúvidas. Se há "usurpação de atribuição" esta é, quase sempre, involuntária. A autoridade entende que a atribuição lhe está afeta. Ou que não lhe está afeta.

JoSÉ FREDERICo MARQUES (cf. Instituicões de direito processual civil, 1958, vol. I, pág. 476), citando LOPES DA COSTA (cf. Direito processual civil brasileiro, 1941, vol. I, págs. 235-236), e CosTA MANso (cf. O processo na segunda instância), assinala com precisão que "não é possível haver conflitos entre autoridades judiciárias e autoridades administrativas. Os atos administrativos que invadirem atribuições judiciárias são nulos e deixarão de ser aplicados, quando invocados em juízo. Quer isso dizer que qualquer juiz pode resolver sobre a invalidade do ato. Daí concluir-se que não há conflito de jurisdição, no sentido de conflito entre autoridades judiciárias, de um lado, $\mathrm{e}$, de outro, autoridades administrativas e legislativas. Só se pode entender conflitos entre autoridades judiciárias"

O antigo Ministro do Supremo Tribunal Federal, Orosimbo Nonato, citado pelo professor CaIo TÁcIto (cf. Conflito de 
atribuições, em Repertório enciclopédico do direito brasileiro, vol. XI, pág. 46), assinala que "o conflito de atribuições entre a autoridade administrativa e a judiciária, muito dificilmente se configura. Os casos são tão raros, são tão excêntricos, tão exóticos, como os que GarsonNeT indica, que, praticamente, inexistem. Se a autoridade judiciária tem jurisdição sobre a administrativa - e tem-na, nos limites de suas atribuições o que compete à autoridade administrativa é cumprir o mandamento da autoridade judiciária e não lhe disputar a competência para determinado ato. Conflito de jurisdição entre elas, inexiste, em princípio. De atribuições pode existir, em casos que serão raros, à conta de seu exotismo".

Também o eminente julgador não apreendeu o problema em toda sua profundidade. Os casos não são tão raros, nem tão exóticos, nem tão excêntricos, por um lado; por outro lado, pode a autoridade administrativa "disputar à autoridade judiciária a competência para a prática de determinado ato", nas hipóteses de "atribuições", quando estão em jogo não "decisões judiciais", mas "tarefas administrativas".

A frase "conflito de jurisdição entre elas, inexiste, em princípio" também é suscetível de reparo, porque a parte final "em princípio" não faz sentido, devendo ser substituída por "sempre".

"De atribuições pode existir", por fim, é frase igualmente que merece reparo, porque "conflito de atribuições" é realidade entre nós e não mera possibilidade.

\section{Comentadores do atual CPC}

Ao comentar o artigo 124 do CPC de 1973, novamente Pontes DE MiRanda se equivoca ao escrever com todas as letras: "De qualquer modo, têm de ser observadas, com rigor, todas as regras jurídicas constitucionais que alcançam a competência judiciária e A COMPETÊNCIA ADMINISTRATIVA, QUE AÍ TAMBÉM É PARA JULGAR” (Comentários ao Código de Processo Civil, Rio, $1979,2^{2}$ ed., vol. II, pág. 467). E repete: “A competência, de que se trata, quer a respeito de autoridade judiciária, quer a respeito de autoridade administrativa, é, AÍ, A DE JULGAR. Autoridade administrativa que aí está, em senso largo, é conceito que, no art. 124, se limita À FUNÇÃo DE JULGAMENTo" (Pontes de Miranda, Comentários ao Código de Processo Civil, Rio, 1979, 2. ${ }^{a}$ ed., vol. II, págs. 467-468). 
No Brasil, não existe competência administrativa "para julgar". Não existe "função de julgamento" por parte de autoridades administrativas, nem o legislador pretendeu, no art. 124 do CPC de 1973, que assim se entendesse o dispositivo. Tanto que remeteu a matéria para os regimentos internos dos tribunais.

Tendo comentado os dois Códigos, de modo algum PonTES DE MIRANDA poderia escrever, pelo menos, ao analisar o art. 124, quarenta anos depois, o que escreveu, não atentando para a perfeita colocação que ALFREDo BUZAID deu ao tema a fim de que não se confundisse mais "jurisdição" com "atribuição".

CELSO AGRÍcola BARBI mostra, com apoio em LOPES DA Costa (Direito processual civil, Rio, 2. ${ }^{a}$ ed., 1959, vol. I, pág. 315), que "a autoridade administrativa não é detentora de jurisdição que é, em regra, privativa da autoridade judiciária" (Comentários ao Código de processo civil, 1975, vol. I, tomo segundo, pág. 510).

SÉRgio Sahione Fadel (Código de Processo Civil comentado, Rio, 1981, vol. I, pág. 254) principia a tratar corretamente do assunto, apoiado em CAIo TÁcITo (Conflito de atribuições, em Repertório enciclopédico do direito brasileiro, vol. XI, pág. 46), ressaltando que "o conflito de atribuições diz respeito ao incidente de competência entre uma autoridade administrativa e outra judiciária", mas depois alude à "crescente especialização dos órgãos administrativos para determinados assuntos, EM QUE EXERCEM VERDADEIRA FUNÇÃO JURISDICIONAL, EMBORA NA ESFERA ADMINISTRATIVA" ( $c f$. Código de Processo Civil comentado, Rio, 1981, vol. I, pág. 255) .

órgãos administrativos não exercem função jurisdicional, em nenhuma esfera e, muito menos, na esfera administrativa.

HÉlio TORNAGHI, comentando o CPC de 1973, principia, corretamente, dizendo que "não pode haver conflito de jurisdição entre órgão judiciário e órgão administrativo" (Comentários ao CPC, 2. ${ }^{2}$ ed., 1976, RT, vol. I, pág. 377), mas depois oferece exemplo que não é pertinente à espécie. "Figure-se", acrescenta, "a hipótese de um governador que, por motivos pessoais, desapropria a residência de um banqueiro. Se este recorre ao Judiciário para anular o ato por ser conseqüente ao abuso de poder e a Administração sustenta que só a ela cabe decidir o assunto, o conflito surge e pode ser suscitado" (Comentários ao CPC, 2. ${ }^{\mathrm{a}}$ ed., 1976, RT, vol. I, pág. 379). 
Não há aqui exemplificação de "conflito de atribuições", mas tão somente hipótese de "desvio de poder", motivo jurídico suficiente para a anulação do ato administrativo pelo Poder Judiciário (cf. nosso livro Anulação do ato administrativo por desvio de poder, Forense, 1978, pág. 243 e MANOEL GONÇALVES Ferreira Filho, Parecer, em RDA, 118:431).

\section{A Emenda Constitucional}

Conforme o que determina a Emenda Constitucional n. 1, de 17 de outubro de 1969, art. 119, I, "f", compete ao Supremo Tribunal Federal processar e julgar originariamente os conflitos de atribuições que ocorram entre (a) autoridades administrativas e autoridades judiciárias da União; (b) autoridades administrativas de um Estado e autoridades judiciárias de outro Estado; (c) autoridades administrativas do Distrito Federal e autoridades judiciárias de um Estado; (d) autoridades administrativas dos Territórios e autoridades judiciárias de um Estado; (e) autoridades administrativas de qualquer dos Territórios e autoridades administrativas da União.

Como entender o possessivo "destes"? Refere-se apenas a Territórios? A Territórios e Distrito Federal? Ou refere-se a Estados, Distrito Federal e Estados-membros? A nosso ver refere-se a essas três unidades.

Pelo que, à lista acima devemos acrescentar: (f) autoridades administrativas da União e autoridades judiciárias de um Estado; (g) autoridades administrativas de um Estado e autoridades judiciárias da União.

o Regimento Interno do Supremo Tribunal Federal, art. 6..$^{\circ}$ " $\mathrm{e}$ " repete, ipsis litteris, o artigo 119, I, "f" da Emenda Constitucional n. 1, de 1969.

\section{Conflitos de atribuição, na prática}

Caso antigo, que localizamos, de conflito de atribuição, entre nós, foi o que ocorreu, em 1936, entre o Juiz dos Feitos da Fazenda Municipal e o Prefeito do Distrito Federal, a respeito de mandado proibitório expedido pelo magistrado, a requerimento de comerciante de flores, contra o Prefeito que, no exercício normal do poder de polícia e de acordo com as leis vigentes, proibira o comércio de flores e plantas na área de 300 metros, a partir do centro dos mercados de flores localizados nas proximidades dos cemitérios. Na hipótese dos autos, o interdito proibitório não poderia prevalecer contra o 
ato do Prefeito, impedindo a ação das autoridades municipais no exercício legal de suas funções administrativas, amparadas por lei.

Como diz a ementa do Acôrdão prolatado por uma das Câmaras da Corte de Apelação do Rio de Janeiro, a lei em vigor, na época, admitia a hipótese de conflitos de atribuição entre autoridades judiciárias e administrativas, atribuindo a competência para a solução ao Tribunal de Apelação, não se tratando, no caso, de conflito em matéria judiciária, mas tão-somente em matéria administrativa, na qual as autoridades judiciárias podem ter jurisdição que coincida com as atribuições confiadas a autoridades administrativas (Corte de Apelação do Rio de Janeiro, 1936, em RF, 69:509).

Dois anos depois, o Plenário da mesma Corte de Apelação decidiu ser "impróprio o conflito de atribuição para tornar sem efeito o mandado proibitório expedido pelo Juízo dos Feitos da Fazenda Municipal contra ato do Prefeito do Distrito Federal" (Plenário da Corte de Apelação do Rio de Janeiro, 1938, em RF, $73: 554)$.

Em 24 de setembro de 1941, o plenário do Supremo Tribunal Federal, por maioria, contra o voto de CASTRo NUNES, relator, e de VALDEMAR FALCÃo, teve a oportunidade de examinar pretenso conflito de atribuições entre autoridade judiciária estadual e autoridade administrativa federal, mas não conheceu do conflito, porque se tratava de "desobediência e. não de conflito de atribuições o suscitado pela atitude de autoridade administrativa federal que se nega a cumprir requisição de processo administrativo, feito por autoridade judiciária estadual" (STF, em RF, 90:99).

Vale a pena ler o debate havido em plenário, entre os Ministros CASTRo Nunes e ORosimbo NonAto, bem como o magnífico Parecer exarado, na ocasião, pelo Procurador Geral da República, GabRIEL DE RESENDE Passos.

Outro exemplo típico de conflito de atribuição positivo foi suscitado em São Paulo, certa ocasião, entre o Chefe do Executivo e o Presidente do Tribunal de Apelação, achando-se ambos competentes para a prática de determinado ato administrativo.

Vago o cargo de Secretário Diretor Geral do Tribunal de Apelação do Estado, em decorrência do falecimento do titular, achou-se competente o Interventor Federal para efetuar a nomeação de substituto para o cargo do falecido, designando para o lugar o Diretor da Diretoria Judiciária da Secretaria 
do mesmo Tribunal, de acordo com o diploma estatutário vigente, na época (art. 12 do Decreto-lei Estadual n. 12.273, de 28-10-1941 e art. 43, "g" da Constituição Estadual).

Por sua vez, o Presidente do Tribunal de Apelação entendeu que lhe cabia a competência para aquela nomeação, pelo que se suscitou o conflito, erradamente endereçado ao Supremo Tribunal Federal, tendo a Magna Corte decidido com precisão: "O Supremo Tribunal Federal não é competente para dirimir conflito de atribuição entre Interventor Federal e Presidente de Tribunal de Apelação, agindo ambos, na esfera administrativa: a competência é do Tribunal de Apelação. 0 Interventor Federal é autoridade estadual, quando pratica os atos administrativos do Estado que dirige" (STF, em RT, 158:855. Obs. O processo, que recebeu o número 1.500, foi, entretanto, catalogado como de Conflito de Jurisdição).

No caso, as duas autoridades se avocaram a faculdade de editar o ato administrativo de provimento de cargo público - ato de nomeação -, configurando-se a hipótese de conflito de atribuição e não de conflito de jurisdição, já que se tratava de ato de administração e não de ato de jurisdição.

Neste exemplo, como decidiu com acerto o Supremo Tribunal Federal, cabe a resolução do conflito positivo de atribuição ao Tribunal de Apelação que, a nosso ver, age nas vestes de administrador e não no exercício de suas funções jurisdicionais, pois não se trata de competência "para julgar" e sim de competência "para administrar" (Contra: MÁRIo MASAGÃo, Curso de direito administrativo, 5. ${ }^{\mathrm{a}}$ ed., 1974, pág. 320).

Podem as autoridades em conflito manifestar-se, quer na fase de conhecimento e decisão de algum assunto, quer na fase executória de deliberação. A ocorrência de conflito de atribuiç̧̃ão supõe necessariamente que nenhum dos órgãos conflitantes seja hierarquicamente subordinado ao outro, pois, nessa hipótese, a decisão do órgão superior resolveria a questão.

Certa ocasião ocorreu conflito positivo de atribuição entre - Juiz de Menores da Capital do Estado de São Paulo e o Superintendente Regional do Departamento de Polícia Federal, no mesmo Estado, já que ambas as autoridades, no exercício do poder de polícia que lhes cabia, entendiam serem competentes para editar Portarias para a fiscalização de diversões públicas (caso "Flipperama"). Se tivesse sido suscitado o conflito, competente para resolvê-lo teria sido o Supremo Tribunal Federal, a cujo plenário ficaria afeta a resolução administrativa desse choque de competências. 
Nítido conflito de atribuição ocorreu em São Luiz do Maranhão, sendo suscitante o Juízo dos Feitos da Fazenda Pública e suscitada a Alfândega de São Luiz, ou seja, houve choque de competência administrativa entre o Juiz dos Feitos da Fazenda Pública da Comarca da Capital do Estado do Maranhão e o Inspetor da Alfândega de São Luiz, pleiteando o suscitante o prosseguimento no processo de busca e apreensão, requerido, preventivamente, pelo Procurador da República.

Suscitado o conflito de atribuições perante o Supremo Tribunal Federal, a Corte Suprema conheceu do conflito, julgando competente a autoridade administrativa, ou seja, o Inspetor da Alfândega, ordenando que lhe fossem remetidos os autos da referida diligência preliminar para que prosseguisse no respectivo processo fiscal (STF, em RDA, 53:206).

Outro caso interessante de conflito de atribuiçoes ocorreu entre o Juiz de Direito da Vara Criminal e o Superintendente Regional da Polícia Federal a respeito do exercício do poder de polícia para a fiscalização da freqüência de menores de dezoito anos a espetáculos cinematográficos, concluindo o Supremo Tribunal Federal que a competência cabe ao Juiz de Menores, o qual pode contar com o auxílio da Polícia local (STF, em RTJ, $66: 613$ ).

Em 20 de dezembro de 1946, o Supremo Tribunal Federal teve a oportunidade de examinar pseudoconflito de competência administrativa, em que figurava como suscitante empresa do Distrito Federal e suscitada a Inspetoria de Rendas do Estado do Rio, não conhecendo, porém, do conflito, e ordenando, por unanimidade, fosse convertido o julgamento em diligência para que se oficiasse ao Ministro da Justiça, no sentido de ser determinado ao Interventor Federal a tomada de providências necessárias.

Concluiu o Supremo Tribunal Federal que os fatos levados à Corte não configuravam conflito de atribuições, sendo, na realidade, conflito entre duas autoridades fiscais, uma do Estado e outra da União, não se envolvendo, no caso, qualquer autoridade judiciária, pelo que o pedido, nos termos em que está redigido, é verdadeira consulta e, já que o Supremo Tribunal Federal não é órgão consultivo, a questão só poderá ser decidida pelos meios próprios que a lei faculta (STF, em RDA, 8:123).

\section{Natureza jurídica do ato que dirime o conflito}

Se, no âmbito interno de cada um dos Poderes e, em especial, na esfera do Poder Executivo, ocorrem a todo instante 
conflitos de atribuições, cuja solução é matéria administrativa de fixação de competência afeta ac superior hierárquico das autoridades administrativas, em conflito, também na órbita externa o choque de competência entre autoridades judiciárias e autoridades administrativas, em assunto administrativo, é matéria administrativa e não jurisdicional, pelo que a natureza jurídica do ato do Poder Judiciário, que dirime o conflito de atribuição, em qualquer grau de jurisdição, é igualmente de natureza administrativa, funcionando esse Poder como o superior hierárquico das autoridades conflitantes, cabendo, no caso, recursos administrativos e não recursos judiciais, à decisão proferida.

Não pensava desse modo MÁrio MASAGÃo, para quem, "nesses casos, as dúvidas de atribuição são resolvidas pelos órgãos do Poder Judiciário, não mais nas vestes de administradores, mas no exercício de suas funções jurisdicionais" (Curso de direito administrativo, 5. ${ }^{\mathrm{a}}$ ed., 1974, pág. 320).

Cumpre ainda observar que, ao resolver conflitos de atribuição, o Poder Judiciário não age como órgão consultivo, caso ocorram dúvidas sobre a existência ou não de choque de competência administrativa. Assim, certa feita, bacharel que se inscrevera a concurso para a magistratura, suscitou conflito de atribuições, porque a Banca Examinadora era integrada por dois juízes de direito, AgUIAR DIAS e PINTo FALCÃo, mas o Supremo Tribunal Federal não conheceu do conflito, porque tal não ocorre "entre autoridades administrativas e magistrados, quando estes não funcionam como tais" (STF, em RF, $156: 104)$.

Nos dois exemplos que demos, o Supremo Tribunal Federal ressaltou com veemência que não é órgão consultivo ( $\mathrm{STF}$, em RDA, 8:123 e STF, em RF, 156:104), pelo que as questões que lhe forem submetidas devem ser, realmente, choques concretos, de fato, e não hipóteses de dúvida sob a forma de consultas. 